Commentary

\title{
From Selective Exposure to Selective Information Processing: A Motivated Reasoning Approach
}

\author{
Lindita Camaj \\ Jack J. Valenti School of Communication, University of Houston, Houston, TX 77204, USA; E-Mail: Icamaj@uh.edu
}

Submitted: 20 June 2019 | Accepted: 22 June 2019 | Published: 30 July 2019

\begin{abstract}
Literature suggests that while without doubt people engage in selective exposure to information, this does not entail that they also engage in selective avoidance of opinion-challenging information. However, cross-cutting exposure does not always lead to dispassionate deliberation. In this commentary I explore psychological conditions as they apply to attitudebased selection and make an argument that selectivity does not stop at exposure but continues as audiences engage with information they encounter and incorporate in their decision-making. I propose the theory of motivated reasoning as a rich theoretical underpinning that helps us understand selective exposure and selective information processing.
\end{abstract}

\section{Keywords}

audience; information; information processing; media; motivated reasoning; selective exposure

\section{Issue}

This commentary is part of the issue "Selective Exposure in a Changing Political and Media Environment", edited by María Luisa Humanes (University Rey Juan Carlos, Spain).

(C) 2019 by the author; licensee Cogitatio (Lisbon, Portugal). This article is licensed under a Creative Commons Attribution 4.0 International License (CC BY).

\section{Introduction}

It is assumed that the prospects for a deliberate democracy are dire in a society where individuals seek only information that supports their beliefs and limits their exposure to other perspectives (Cohen, 1997). The affordances provided by the current media environment for selective exposure represent the worst nightmare for deliberate theorists as they create the perfect conditions for ideological echo chambers. Thus, the renewed interest in this topic comes as no surprise as scholars grapple to understand and predict the causes and consequences of information selectivity.

Indeed, the concept of selective exposure is not new (Klapper, 1960) and the literature already offers rich theorizing on the topic. Scholarly work shows that news consumers tend to select media content that is in line with their attitudes across print, online media, and broadcast content. As Garret (2013) eloquently puts it: "The central question is no longer whether or not attitudes influence media exposure decisions - there is little question that they do. Instead, scholars are most concerned with the conditions under which selectivity occurs" (p. 247).
In this commentary I explore psychological conditions as they apply to attitude-based selection and make an argument that selectivity does not stop at exposure but continues as audiences engage with information they encounter and incorporate in their decision-making. I emphasize the importance of understanding of processes that lead to selective exposure and selective information processing and propose motivated reasoning as a rich theoretical underpinning that helps us understand both.

\section{Attitude-Based Selectivity}

The phenomenon of selective exposure can be defined as "any systematic bias in selected messages that diverge from the composition of accessible messages" (Knobloch-Westerwick, 2015, p. 3). Literature shows that media consumers tend to select media content that is in line with their attitudes (Garrett, 2013; Klapper, 1960), with partisan and ideological attitudes taking central stage in political communication (Mutz \& Martin, 2001).

Cognitive dissonance theory (Festinger, 1957), the most applied theoretical foundation to selective expo- 
sure, explains that people are predisposed to seek exposure to information they agree with and avoid conflicting information that might cause psychological discomfort. People are motivated to reduce dissonance by seeking out reinforcing information and avoiding challenging points of view. Moreover, hostile media bias theory explains the tendency of partisans to judge media coverage as unfavorable to their point of view (Vallone, Ross, \& Lepper, 1985), which compromises their trust in media. Rather than affecting media exposure in general, trust in mainstream media affects primarily media choice (Rimmer \& Weaver, 1987).

Conceptually, these theories explain the early stages of the deliberate media engagement (i.e., the motivation behind the tendency to turn to mass media for information in the first place), conceptualizing media use as instrumental and purposive. But little is known what happens in the link between exposure and opinion formation.

\section{Conflicting Evidence: Reinforcement Seeking and Challenge Avoidance}

Increasingly the literature is finding that people exhibit a preference for opinion-reinforcing political information without systematically avoiding opinion challenges, contradicting "the common assumption that reinforcement seeking and challenge avoidance are intrinsically linked aspects of the selective exposure phenomenon" (Garret, 2009). A large and stable majority of Americans maintain a diverse news diet, consuming smaller amounts of both pro- and counter-attitudinal partisan sources (Garrett, Carnahan, \& Lynch, 2013). Studies have found that people with high political interest and high partisanship are the most likely to pay attention to the political news across all media types, partisan and centric (Camaj, 2018). Self-reported measurements can inflate ideological exposure, and when observed in real life situations people's media repertoires are very diverse rather than segregated in echo-chambers (Dvir-Gvirsman, Tsfati, \& Menchen-Trevino, 2016).

In a more refined elaboration of the cross-cutting exposure phenomena, recent scholars distinguish between selective exposure and selective avoidance (Garret, 2009; Garrett et al., 2013). This line of scholarship argues that seeking opinion-reinforcing and avoiding opinionchallenging information are not equivalent behavior based on empirical findings that suggest that while audiences seek out ideologically aligning media, they do not actively avoid cross-cutting news sources. Motivating factors for cross-cutting exposure range from anxiety (Valentino, Banks, Hutchings, \& Davis, 2009), expected utility (Knobloch-Westerwick \& Kleinman, 2012), and to better defend their position (Hargittai, Gallo, \& Kane, 2008).

While this literature provides a clear picture on how we physically engage with media sources, it does not provide any clarity on how we mentally engage with informa- tion gained from those sources. Yet, in an environment of cross-cutting exposure only research on message processing bias can help us understand whether individuals favor information that aligns with preexisting attitudes over attitude-challenging information.

\section{From Selective Exposure to Selective Information Processing}

In recent years scholars in political communication have increasingly turned to motivated reasoning theory (Kunda 1990; Lodge \& Taber, 2013) as a framework for understanding selective exposure (Camaj, 2018; Stroud, 2011; Wojcieszak, 2019). According to this theory, people are motivated by two types of goals when seeking out information: accuracy goals predispose people to reach correct conclusions, and directional goals motivate people to reach their preferred conclusions.

Driven by their desire to know the truth, individuals in the first group are motivated to seek accurate information across media sources that helps reach accurate conclusions. Conversely, directional goals motivate people to attend to political cues or heuristics, such as party identity and their own predispositions (Bolsen, Druckman, \& Cook, 2014), when selecting information in order to arrive at particular conclusions that make them feel validated. Thus, individuals motivated by directional goals seek attitude-congruent information.

In the context of a US election a recent study suggested that interested partisans, those with directional goals, are more likely than other people to engage in cross-network news media exposure (Camaj, 2018). Yet, cross-network viewing did not generate more moderate opinions. On the contrary, people who were more prone to consume news on network and cable television, were also the ones who expressed the most extreme opinions about political candidates, suggesting that media effects occurred mostly as a consequence of biased information processing.

Motivated reasoning represents a psychological moderator that explains not only patterns of information seeking and news selection, but also patterns of information processing that happens after the initial exposure. Motivations for information affect the evaluation of evidence and how it applies to one's attitudes. People who are motivated by accuracy goals are more likely to evaluate information more even-handedly and process information more deeply (Kunda, 1990; Lodge \& Taber, 2013; Rudolph, 2006). Conversely, people motivated by directional goals process more critically information from sources they disagree with and give weight to information consistent with their preexisting beliefs more heavily. Directional goals motivate people to attend to political cues or heuristics (Bolsen et al., 2014) so they process information in biased or partisan ways, disregarding information that contradicts their point of view.

Most theorists align accuracy motivations with central processing, while directional goals with peripherical 
processing of information. This train of thought emphasizes that the durable partisan identities are cued and activated by content and guide reasoning about refusal of counter-attitudinal information in an automatic and effortless way (Leeper \& Sloth, 2014).

Recently, thought, there is a recognition that the strategies employed in selection during information processing can be consciously or unconsciously (Taber \& Lodge, 2012). After all, it takes effort to recognize counter-attitudinal arguments and find reasonings to devalue them. As Taber and Lodge (2012) argue, "defense of one's prior attitude is the general default when reasoning about attitudinally contrary arguments, and it takes dramatic, focused intervention to deflect people off a well-grounded attitude" (p. 249). Thus, biases in information processing can result from varied motivation-effort interactions (Leeper \& Sloth, 2014).

\section{Conclusion}

Literature suggests that while without doubt people engage in selective exposure to information, this does not entail that they also engage in selective avoidance of opinion-challenging information in a systematic way (Garret, 2009). Rather, there is ample evidence that people engage in cross-cutting exposure more often than they don't. But, as Garret (2013, p. 249) argues, “individuals' tolerance toward (and occasional appetite for) counter-attitudinal political news should not be confused with dispassionate deliberation." By focusing our empirical attention on the selective exposure to sources of information or content, we are missing an important facet of selectivity, namely the selectivity and biases as they apply to information processing in decision-making.

In an environment of cross-cutting exposure, the theory of motivated reasoning (Kunda, 1990) is well suited to provide a theoretical foundation to explore whether and under which circumstances individuals favor information that aligns with their preexisting attitudes over attitude-challenging information. There is a critical need to look into "the black box" in order to understand the multi-faced aspects of selectivity in a more holistic way.

\section{Acknowledgments}

Thank you to the guest editor María Luisa Humanes for putting together this thematic issue and inviting me to be part of the stimulating discussion on the topic of selective exposure that this issue puts forth.

\section{Conflict of Interests}

The author declares no conflict of interests.

\section{References}

Bolsen, T., Druckman, J. N., \& Cook, F. L. (2014). The influence of partisan motivated reasoning on public opin- ion. Political Behavior, 36, 235-262. https://doi.org/ $10.1007 / \mathrm{s} 1110901392380$

Camaj, L. (2018). Motivational theories of agenda-setting effects: An information selection and processing model of attribute agenda-setting. International Journal of Public Opinion Research. https://doi.org/10. 1093/ijpor/edy016

Cohen, J. (1997). Deliberation and democratic legitimacy. In J. Bohman \& W. Rehg (Eds.), Deliberative democracy: Essays on reason and politics (pp. 67-92). Cambridge, MA: MIT Press.

Dvir-Gvirsman, S., Tsfati, Y., \& Menchen-Trevino, E. (2016). The extent and nature of ideological selective exposure online: Combining survey responses with actual web log data from the 2013 Israeli elections. New Media \& Society, 18(5), 857-877. https:// doi.org/10.1177/1461444814549041

Festinger, L. (1957). A theory of cognitive dissonance. Evanston, IL: Row Peterson.

Garrett, R. K. (2009). Politically motivated reinforcement seeking: Reframing the selective exposure debate. Journal of Communication, 59, 676-699. https://doi. org/10.1111/j.1460-2466.2009.01452.x

Garrett, R. K. (2013). Selective exposure: New methods and new directions. Communication Methods and Measures, 7, 247-256. https://doi.org/10.1080/ 19312458.2013.835796

Garrett, R. K., Carnahan, D., \& Lynch, E. K. (2013). A turn toward avoidance? Selective exposure to online political information, 2004-2008. Political Behavior, 35, 113-134. https://doi.org/10.1007/s11109-0119185-6

Hargittai, E., Gallo, J., \& Kane, M. (2007). Crossideological discussions among conservative and liberal bloggers. Public Choice, 134(1), 67-86.

Klapper, J. T. (1960). The effects of mass communication. Glencoe: The Free Press.

Knobloch-Westerwick, S. (2015). Choice and preference in media use. Advances in selective exposure theory and research. New York, NY: Routledge.

Knobloch-Westerwick, S., \& Kleinman, S. (2012). Preelection selective exposure: Confirmation bias versus informational utility. Communication Research, 39, 170-193. https://doi.org/10.1177/ 0093650211400597

Kunda, Z. (1990). The case for motivated reasoning. Psychological Bulletin, 108, 480-498. https://doi.org/10. 1037/0033-2909.108.3.480

Leeper, T. J., \& Slothuus, R. (2014). Political parties, motivated reasoning, and public opinion formation. Advances in Political Psychology, 35, 129-56. https:// doi.org/10.1111/pops.12164

Lodge, M., \& Taber, C. S. (2013). The rationalizing voter. Cambridge: Cambridge University Press.

Mutz, D. C., \& Martin, P. S. (2001). Facilitating communication across lines of political difference: The role of mass media. American Political Science Review, 95(1), 97-114. Retrieved from https://www. 
jstor.org/stable/3117631

Rimmer, T., \& Weaver, D. (1987). Different questions, different answers: Media use and media credibility. Journalism Quarterly, 64, 28-44. https://doi.org/10. $1177 / 107769908706400104$

Rudolph, T. J. (2006). Triangulating political responsibility: The motivated formation of responsibility judgments. Political Psychology, 27, 99-122. https://doi. org/10.1111/j.1467-9221.2006.00451.x

Stroud, H. J. (2011). Niche news: The politics of news choice. New York, NY: Oxford University Press.

Taber, C., \& Lodge, M. (2012). The scope and generality of automatic affective biases in political thinking: Reply to the symposium. Critical Review, 24(2), 247-268. https://doi.org/10.1080/08913811.2012.719664
Valentino, N., Banks, A., Hutchings, V., \& Davis, A. (2009). Selective exposure in the internet age: The interaction between anxiety and information utility. Political Psychology, 30, 591-613. https://doi.org/10.1111/j. 1467-9221.2009.00716.x

Vallone, R. P., Ross, L., \& Lepper M. R. (1985). The hostile media phenomena: Biased perception and perceptions of media bias in coverage of the "Beirut Massacre". Journal of Personality and Social Psychology, 49, 577-585. http://dx.doi.org/10.1037/0022-3514. 49.3.577

Wojcieszak, M. (2019). What predicts selective exposure online: Testing political attitudes, credibility, and social identity. Communication Research. https://doi. org/10.1177/0093650219844868

\section{About the Author}

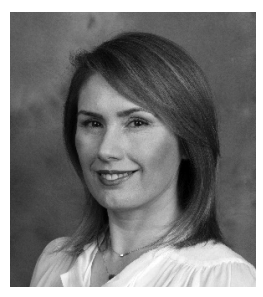

Lindita Camaj is an associate professor at the Jack J. Valenti School of Communication, University of Houston. She received her PhD at the Indiana University. Her broad research interests include news media role during electoral campaigns, state-press relationships in Eastern Europe and Freedom of Information (FOla) legislation. As a multi-method scholar grounded in the agenda setting and agenda building scholarship, her research explores individual and societal factors that determine the impact of mass media on how we perceive and engage with the political world. 